\title{
CREATION OF CORPORATE IDENTITY: THE ROLE OF RITES AND SYMBOL IN MANAGEMENT ${ }^{1}$
}

\author{
YI ZHU \\ UNIVERSITY OF TSUKUBA
}

\begin{abstract}
This paper aims to examine by anthropological methods the ways in which a corporate entity's rites and symbols in management help construct a unique corporate identity, and the ways in which community members can cultivate a strong sense of belonging. Numerous management scientists believed that corporate identity was a fixed concept that could be measured scientifically. This perspective overlooks its fluidity and the impacts of routines and symbolic figures on identity-building. This study will use the case of a Japanese ramen shop in Cambridge, Massachusetts (USA), to examine one of the unique aspects of Japanese management, which is to use daily routines and symbols to enhance collectivism. This paper uses the anthropological notion of identity building to offer a new perspective on management studies and to deepen the understanding of management in the Japanese context.
\end{abstract}

Keywords: corporate identity, rite, symbol, management, Japan

\section{Introduction}

One sunny day in May 2017, I visited a unique Japanese jiro ramen shop in Cambridge, Mass, which has successfully gained brand recognition among the locals and remains very profitable. The shop was named AKI (a pseudonym) ${ }^{2}$ with the philosophy of sharing people's dreams in the shop. Jiro ramen is a huge bowl of ramen with a large

1 This research is supported by Grants-in-Aid for Young Scientists B, Japan Society for the Promotion of Science.

${ }^{2}$ Names of the shop and employees are pseudonymous, and the sources of any information that might reveal their identities will not be clarified. 
volume of "chashu" (marinated braised pork), thick noodles, and garlic (sometimes optional). The reason I became interested in this shop is its unique concept and how they interpret the meaning of ramen and their business. In fact, after my initial interview request, an AKI staff member replied by saying they would decline an interview if I was interested only in their ramen, because they are not simply a ramen shop but a "dream workshop". This surprised me because I did not expect to receive such a reply, but I was able to get an interview and later had the opportunity to engage in participant observation as well. I wondered at that time what they meant by "dream workshop" and how that could relate to ramen. With these and other questions in my mind, I took the metro to AKI, hoping to find some answers.

After alighting at a metro station close to Harvard University, I saw several shopping malls on my right and various retail shops on my left. It was a weekday afternoon. The surroundings were quiet, and there was less traffic than downtown. I walked a few minutes until I saw a blue sign with the letters AKI on my right. A glance through the large glass shop window showed a unique shop layout, where the wooden tables were all facing the kitchen and customers turned their backs to the passers-by. I entered the shop and found it painted in blue, with various works of art on the walls, including manga-style illustrations of the shop master (owner), Mr. Tanaka, having conversations with people. I also noticed many messages painted on the back of each chair. All of these messages were related to "the dream".

While I was waiting for my interviewee, I saw several customers who seemed to have finished their ramen suddenly stand up and talk to the staff working in the kitchen one by one. What were they doing? I asked myself, and soon realized this is one of the representative ritualistic practices in AKI-customers sharing their dreams. In fact, AKI posts many video clips of customers sharing their dreams on their Facebook pages. Sharing dreams and disseminating this concept across cultures are the major stated goals of AKI; they consider ramen to be a tool they use to realize these goals. According to the philosophy of Master Tanaka, finishing a huge bowl of jiro ramen is similar to the process of achieving the dream - difficult, but enjoyable. Who are the AKI members and customers, or, as they are called, the "dream chasers"? What were they attracted to? Have they constructed a AKI identity? If yes, what were the influential elements of this process?

This paper aims to answer these questions, based on fieldwork at AKI in May 2017, by exploring its identity and how the dream-sharing rituals and underlying symbols contribute to its identity-building. The article then reviews previous literature on corporate identity, rites, and symbols, and 
then introduces AKI and its symbolic philosophy, which was created by Master Tanaka. It delves further into AKI to discuss how its philosophy has been represented at the shop to form a sacred space, and how it has been enhanced in the process of ritualistic practices among the members and interactions with the customers to create collective experiences. Finally, it considers possible links between ritualistic practices, symbols and the formation of identity in a business organization, and outlines the implications of these links to both the academic and practical world.

\section{Corporate Identity, Rites, and Symbols}

According to Erik Erikson (1959), one of the main tasks in adolescence is the search for identity, a sense of who one is and what one stands for. Adolescents seek to identity their beliefs, values, and life. Corporate identity has two levels: individual and organizational (Bernstein, 1984). Organizational or collective identity represents the company as a whole, and also influences how the company will be evaluated by stakeholders and customers (Olins, 1990). This paper will focus on the collective aspect of identity to explore how shared belief among organizational members is expressed in their identity.

There have been many studies across various disciplines about identity. Cornelissen and Elving (2003) found several patterns in the literature on corporate identity. The first is about the symbolic outward presentation of a company, such as company logo, seen mostly in the public relations and communications industry (see Brown et al., 2006). Van Riel (1995:340) says that this pattern "equate[s] corporate identity with graphic design". The second is to personify the organization to empower individuals, indicating that every member in the organization is entitled to have his or her own identity. The first two were from practitioners' perspectives, while the third pattern is academic in purpose, in order to better understand organizational reality by perceiving the organization as an organism. In the third type, the term "corporate identity" is more like a living organism with distinctive features of the organization.

One of the common tendencies among scholars of corporate-identity management is that their research aims were mainly for stakeholders, which underestimated the impact of employees who contribute largely to the process of creating a corporate identity. This paper categorizes previous literature on identity-building into the following themes. One is to treat identity as an essential tool to strategically brand itself and favour the stakeholders (see van Riel, 1995; Balmer and Gray, 2000), or as an image of an organization that represents its uniqueness to the outside 
world (Kennedy, 1977; Dowling, 1986). They believe that identity as a phenomenon can be controlled, and individuals can be produced appropriately (Marwick and Fill, 1997; Alvesson and Willmott, 2002). This is also considered to be categorized in the stakeholder theory, summarized by Kitchen et al. (2013), which largely focuses on marketplace interaction, and on maximization of stakeholders' profits.

The second is to analyze identity from employee perspectives, especially their organizational behaviours (Riketta 2005; Punjaisri et al. 2009). Analyzing how employees regard themselves in the organization, and what kind of language they use to describe their identity, are keys to this type of research; it therefore largely focuses on the individual aspect or "self-categorization", as noted in Kitchen et al. (2013). The third pattern regards identity-building as a process of distinguishing others from organization members through boundary-building, ritual practices and symbols - in other words to not only discuss internal solidarity but also external identity. Authors that fall into this category operate to some extent like adherents of organizational theory, which focuses on exploring organizational culture and values, but their research methodology and analytical framework largely differ across disciplines.

This paper utilizes a similar perspective to that of the third theme, correlating to the boundary-building theory proposed by Barth (1998) who claims that building an ethnic boundary is one of the ways to distinguish insiders from outsiders, which expresses a population's unique identity to the outside world. While this paper focuses on business organizations rather than ethnic groups, this theory could be used to understand how AKI utilizes various rules to integrate corporate identity, an expression of corporate ideology created by the management, through various policies, goals, and missions. AKI's identity has not only been influenced by the master's philosophy, but was also created and consolidated through a process of sharing that philosophy with people who possess similar beliefs. In other words, the "artificial" corporate identity can become "authentic" if it has been widely shared by the organizational members.

Identity-building and its relationship to rites and symbols has long been a subject of discussion in academic publications. Many have claimed the importance of ritual practices in forming boundaries, identities and culture. Durkheim (1915) argues that ritual acts regulate their internal solidarity while enhancing their external identity. As for the deconstruction and reconstruction of identity, ritual is the basic notion covering all organized forms that this can take (Koster 2003:12). De Coulanges and Denis (1873) also wrote that ritual has a mechanism that maintains boundaries between group members and outsiders, and that ritual practices 
express and sustain the unique identity shared among the people. Frost et al. (1985) claim that symbolism of rituals and how the events and experiences are interpreted and influenced by the groups play a significant role in further exploring an organization's culture.

Some scholars who analyzed identity from a management perspective pointed out that the lack of appropriate corporate control through ritual practices and symbols can be an obstacle to identity-building. Meyer and Rowan (1977) suggest that formal structures in an organization are usually used to propagandize its ceremonial reasons so that employees will perform in the way the company desires. Alvesson and Kärreman (2001: 19) investigate a consultancy firm and conclude that one of the reasons for a company's failure to implement human resource management practices is that it lacks organizational symbolism, and is therefore unable to symbolize rationality and commitment to people-improvement as well as to a highly competent workforce. Simoes, Dibb, and Fisk (2005) claim that corporate identity management involves diffusion of the company's missions, the pursuit of brand consistency with the company's symbol, and the implementation and support of visual systems.

Other scholars analyzed various subjects to explore how collective experiences are cultivated during, or as the result of, ritual practices and symbolic figures. Zepp (1997) examines the compact capitalist worlds of American shopping malls, and describes how they connect to symbolism of the centre by exploring the cultural and religious significance of people going to malls and the way that the mall becomes the centre of people's daily lives. Kaplan (2009) described how music radio shapes collective experiences and national sentiment - in particular, how a unified musical atmosphere is created and how this atmosphere affirms national identity through the construction of collective experience. Spickard (2005) discusses Catholic ritual practices and concludes that weekly masses reinforce identity by guiding the experiences of people who participate in the ceremonies. Spickard argues that this has expanded from the inner realm to the outside world, and points out the necessity of studying the experiential dimension of ritual and symbol.

Groups of scholars in Japanese studies have explored the relationship between religion and management in various business scenes. Sumihara (2009) and Wong (1999) analyze how entrepreneurs' religious beliefs provide the spiritual foundations of their management philosophies and actual managerial practices. Matsunaga (2009) wrote about how the spatial arrangement of supermarkets is, in fact, based on church architecture in the United Kingdom. Hamada (2013:25) described three domains of a corporate ritual feast in a Japanese firm: the ritualization process, the role 
of rituals, and how an individual interprets this process. This paper uses Hamada's three domains to explore the case of AKI.

While some scholars claim that corporate identity is something that can be managed and controlled by an organization's administrators, others emphasize its fluidity, like the perspective commonly applied to discourses on cultural identity. This paper considers how the fluid identity has been constructed from the master's philosophy, ritual practices, and symbolic figures. The important question we need to ask before conducting research is how to tell if one particular corporate identity was in fact the real identity: do employees who say they believe in this identity, actually do so? Scholars have attempted to develop a variety of rubrics for identifying the true face of corporate identity, including customer surveys (Gray 1985), ethnographies (Balmer 1995) and semi-structured interviews (Bernstein 1984). This paper will combine some of these methodologies, especially participant observation and open-ended interviews, with the aim of considering both management and employees. As Nakamaki and Hioki (2009) wrote, considering business practices from an anthropological perspective requires us to explore both the rational (the company that pursues efficiency) and irrational elements (cultural aspects) that coexist in a given organization.

As stated above, this paper is based on fieldwork conducted in May 2017 in the AKI shop in Cambridge, Mass. Data without citations were derived from participant observations and interviews. Pre-interview communication was achieved through Facebook, the social networking service. Interviews were conducted with five individuals at the shop, including one general manager, three full-time employees, and one volunteer. All of them were male and in their early twenties to thirties, except the volunteer, who was in his forties. The volunteer was from Japan and travelled to Cambridge to learn from the AKI master. Others recognized themselves as either Japanese Americans or simply as locals. The fieldwork time was short compared to the traditional participant observation, but through in-depth discussion with the members at the AKI shop and participant observation, I was able to grasp to what extent to which the members have shared the master's philosophy and how it was expressed in constructing a sacred space and unique identity. This paper now moves to an introduction of the financial status and historical development of AKI and then to a discussion on the master's philosophy, ritual practices, and symbols. 


\section{Dream Workshop: AKI}

Tanaka, the master of the Cambridge AKI, opened his first jiro ramen shop in Cambridge in October 2012, making his one of the earliest such establishments in the United States. In 2016, AKI earned USD 450,000, with a net profit of USD 150,000; they have never had a deficit since opening. In September 2017, they opened an udon shop in Cambridge called AKI UDON, based on a similar concept, and also expanded its business "back" to Japan, opening an AKI in Tokyo. ${ }^{3}$ According to one respondent, the concept at AKI Cambridge is different from that of the first shop Tanaka opened in Kyoto in 2006. Prior to AKI, Tanaka operated several ramen shops in western Japan under the name of the first shop, which were taken from song lyrics. ${ }^{4}$ In 2008, Tanaka declared that he would open a shop overseas by 2018 . He passed mastership of his shops to others and went to the United States in 2011, opening his first shop one year later.

As the shop name suggests, AKI is a place for people to share their dreams, although only customers who have finished the noodles and the ingredients in their bowl of ramen are allowed to do so. The process of sharing dreams is slightly different between AKI's US and Japanese locations. Customers in the Cambridge shop mostly share their dreams in front of other customers, while customers in Japan can choose to either write their dreams on a piece of paper, or to speak them out loud.

The goal of AKI is not to increase financial profits, but rather to increase the number of shared dreams. In 2016, 20,000 dreams were shared in AKI Cambridge; the goal for 2017 was 40,000. In fact, AKI regularly updates its Facebook page regarding the latest number, and calls it a "dream counter". The ultimate goal of Tanaka is to spread this concept in 195 countries by opening more ramen shops and cafes until 2030, to increase the number of "nakama" (friends, or buddies) who share similar beliefs and support each other in achieving their dreams. "Nakama" in AKI Cambridge indicate customers, full-time regular members, and 150 volunteers working at the shop, including university students, business practitioners, and exchange students.

One of the symbols at AKI Cambridge is Tanaka and his philosophy. Who is Tanaka? What is the logic of his philosophy, and how does it

3 The mastership is arranged under the practice of "norenwake" (licensed), which is slightly different from a franchise. The former practice requires the future masters to learn the necessary skills in the "authentic" shop before they run one independently. The standards of loyalty and operation models differ by company.

${ }^{4}$ Based on personal communication with one of the informants in May 2017. 
influence shop operations? The following section introduces his career path based on the interviews and discusses how sharing dreams plays a role in his philosophy.

\section{Symbol: Master and His Philosophy}

The master of AKI, Mr. Tanaka, was born in 1979, and after graduating from a local elite high school, he went to Tokyo to pursue his dream of being a comedian while many of his classmates entered well-known universities. One of his motivations for leaving his hometown and pursuing his dream was a desire to be different from his classmates. During his first year out of school, he did various part-time jobs, but it was a bowl of ramen that changed his career plan. He was attracted to the shop atmosphere and the taste of ramen, and decided to learn more. After working there and serving as shop manager for several years, he started his own shop in Kyoto. In the first few months, the shop did not prosper, and many employees resigned, but after closing and reopening a number of times, it started to turn around. Since being employed as a shop manager, he had had the dream of opening an overseas ramen shop by 2018, and this dream continued even after he had his own shop in Kyoto. He sold all his shop masterships and went to the United States in 2011. One of his reasons for going overseas was to become somebody significant; he felt that it would be meaningless to live in one town for the rest of his life. Now he operates one shop in Cambridge, and a Japanese student of his method, who worked with him in Cambridge, opened an AKI in Tokyo.

The key concepts in the Tanaka philosophy are dream-sharing and community-building. The concept of the dream in AKI is slightly different from its conventional meaning, but is roughly synonymous to goals, tasks and wishes. For instance, opening an overseas ramen shop and losing weight could both be counted as dreams, according to Tanaka's definition. Tanaka believes that wishing for something does not mean that you will necessarily actually accomplish it, but rather that it is only after you have accomplished a task that you will know whether you wanted it in the first place. People can use the experience of wish-fulfilment to reflect on what to do next time. The "AKI dream workshop" is a place where people can share their dreams, goals and wishes; finishing a huge bowl of ramen could give them an experience similar to that of achieving a dream. Before people eat jiro ramen, they may need to skip a snack or even a meal, because of the huge portion. They should also take into account the next day's schedule, because the meal contains a large portion of garlic. In another words, they need to sacrifice something to accomplish the goal. 
The eating process could be also challenging because of the size of the portion, but Tanaka thinks that the process is something that can be enjoyable.

Tanaka's philosophy to some extent reflects his frustrations with Japanese society and his hope for young people. One of the reasons he named his first shop was that he felt that failure to achieve one's dreams could be one of the reasons that young people commit suicide in Japan (one of his friends as a youth committed suicide). Tanaka felt that, especially after they turn twenty-one, most Japanese youth give up their childhood dreams to be realistic about their future careers. He hoped that people would find the freedom to share their dreams at AKI. If customers at AKI want to be musicians, they can use the space for performances, and if someone wants to be a painter, he will display their paintings. He also doubted the monetary economy because he believed that the purpose of working is not only to make money, but also to enjoy life.

Community-building is also another key concept in Tanaka's philosophy. There is a practice called the "positive cycle programme", which is similar to bartering, where customers are able to exchange some supplies for a free bowl of ramen. It is conducted regularly at certain periods, and by October 2017 the shop had already given away 150 bowls through this programme. There are several ways to conduct the barter. The first is to cycle the money customers pay for the ramen to the youth, to support their dreams. Tanaka will regularly deliver the money accumulated in the tip jars (called the "positive jar") to give away a free bowl of ramen to some customers who accomplish required tasks. For instance, one day in October 2017, the shop announced on Facebook that customers who satisfied the following requirements could get a free bowl of ramen. There are several fixed terms used particularly for appreciating the customers' participations. The first was to get a "Great Job", or "Perfect" one, in their bowl (to finish all the ingredients and soup was considered "perfect" and to leave the soup was a "Great Job"). The second was to stand up by themselves and share their dreams. The third was to either take their dishes back to the dishwasher or pour water for other customers, or give them a tissue if they needed one. These practices were designed to "create a more communal experience" in the hope that people could feel more at home by eating at AKI. The second way is to provide necessary supplies, such as stationery (colourful marking pens, white boards, flowers, etc.), kitchen towels, and so on, for which customers could also receive a free bowl of ramen. By attracting customers with a free bowl of ramen, this "positive cycle" helps increase the number of shared dreams and builds the strength and size of the AKI community. 
Tanaka is an icon at AKI, as his personal story demonstrates the way that pursuing a dream can have positive outcomes. Without any reliable resources, or proficiency in English before arriving in the United States, many people doubted that he would ever succeed. Nonetheless, after only one year in the States, he opened the shop in Cambridge, accomplishing his dream six years ahead of his 2018 deadline. AKI's financial achievement has also gained the attention of many members. Tanaka's personality is another factor attracting many people to the shop. Many interviewees said that they see him as a mentor rather than an employer, and that his clarity of goal and passion seem to have attracted many young people who are struggling to find their purpose in life. Tanaka teaches numerous people without charge, and offers free ramen to the volunteers as a sign of gratitude. One interviewee commented that Tanaka was even willing to help people get working visas without expecting something from them in return.

Unlike some traditional restaurant owners, Tanaka was neither afraid of someone stealing his ramen recipe nor copying the shop concept, first because the recipe is simple, and second because his ultimate goal is to spread the AKI concept across cultures. One AKI member commented that the recipe was not complicated, so everyone could learn it in quite a short time, but that it would still take time to achieve the particular taste offered at AKI shops. Copying the shop concept is in fact something Tanaka welcomes, because doing so would eventually help AKI accomplish their dreams.

The above shows the cultural logic of Tanaka's philosophy and its emphasis on dream-sharing and community-building. How did Tanaka's philosophy form its unique identity? This next section considers the sacred space of the AKI shop in terms of its physical layout and individual members, in order to illustrate how Tanaka's philosophy has been represented in its physical and psychological contracts.

\section{Sacred Space: Physical Layout and Members}

It takes less than five minutes to travel by metro from AKI to Harvard University, and only 10 minutes to travel to the Massachusetts Institute of Technology. The shop operates both at lunch and dinnertime, with several hours' break in between. It was well known that customers needed to line up during the rush hours, which vary from thirty minutes to three hours. This surprised many Japanese, who warned him that Americans would never queue for food.

The external layout of AKI's Cambridge location is similar to the one 
in Tokyo, as its emphasis is on sharing dreams. The shop sign is painted in white with a blue background, and there are some characters and pictures painted on the shop window. On the upper side of the window is written in large white characters, "This is a place to share dreams. My dream for 2017 is...", and below that are several photos of ramen, priced around USD15 (excluding tip). While Tanaka's underlying philosophy has remained consistent, the logistics of the operation have changed somewhat over time. For instance, when they first opened the shop in Cambridge, because of the limited brand recognition of jiro ramen, they pasted a notice in the shop window to explain that jiro ramen is "the biggest bowl of ramen" and to let customers know that "the chef will ask you 'Ninniku iremasuka?' [would you like garlic?] before serving you the ramen". This rule-based eating at $\mathrm{AKI}$ is not unique among Japanese restaurants, and they believed that these rules were given to customers in advance to help them enjoy the food. This reflects one of the common practices in Japanese business, an emphasis on "kata" (form), and it also correlates to the building of identity boundaries. People who are familiar with the correct "kata" are considered to be a part of the AKI family.

After customers enter, the employees guide them to their seats one by one-all seats face the kitchen. This layout echoes the spatial arrangement of a place of worship, classroom, lecture hall, and so on, where the priest or teacher stands in front while others face him. Two wooden tables are placed in each row and house three black wooden chairs. ${ }^{5}$ On the back of each chair are painted various messages, such as "What is your purpose in life?", "I support your Dream!!", "DREAM BIG and EAT HARD”, and "If you can dream it, you can do it!" After sitting down in a row and looking up, visitors see various photo frames filled with shared dreams. Some dreams mention losing weight, studying harder, or travelling, while others wrote that they aspired to become role models in their community, to create the best company in Japan, and so on. In the middle of the shop wall, the number of shared dreams is written, indicating the current number, and the goal for 2017. The emphasis on sharing dreams in a physical space has also been practiced in AKI Tokyo, where on the top of the menu is written, "Share your dream for 0 Japanese yen" and "We do not make a Ramen. We make your Dream!" at the bottom. This shows the extent to which the physical layout is designed to emphasize the importance of dream sharing

${ }^{5}$ Based on the interviews and second-hand resources, it is clear that some of the physical layout has been changed. For instance, the layout of the tables used to be that customers were face to face, but was changed to facing the kitchen. A tip basket instead of a tip jar was put next to every customer. The photos on the wall were also displayed in a row, rather than randomly. 
in a ritualistic setting.

Before the ramen is served, the shop manager confirms whether or not the customer wants garlic. After the ramen is served, it is ready to be eaten. Many Japanese "jirorian" (those who love jiro ramen) declared that finishing the whole bowl of ramen, including its soup, is a sign of respect to the shop manager. This correlates to the logic of Tanaka's philosophy, in which finishing a huge bowl of ramen is similar to the journey of accomplishing dreams. For those who finished all their ingredients and were willing to share their dreams, it was time to do so. Customers choose either to stand up, facing the kitchen or other customers, or to share them while seated. They give their names, to which other members reply saying, "Hi, [member's name]." Then they start sharing their dreams, sometimes sharing more than one. After sharing, the shop staff applaud and then look at their bowls. If they have finished the whole bowl, including the soup, they would say "Perfect", and if they left the soup, it would be "Great Job". During the whole process, the shop staff would use loud voices to encourage a casual and comfortable environment for the customers. This was Tanaka's idea; he believed that contributing to the local community is also one of the responsibilities and joys of being an AKI member. After customers share their dreams, they pay for their ramen near the entrance, where the tip jar (labelled "positive jar") is located.

The above describes how Tanaka and his philosophy of sharing dreams and community-building are represented spatially. The next section introduces various AKI members to illustrate how rituals are practiced among members, and between members and customers.

\section{AKI Members}

From 2012 until recently, Tanaka operated the shop with the help of hundreds of volunteers, including students of Harvard University, Tufts University, exchange students, and others such as business practitioners and travellers. All of them have registered on the AKI database and have been assigned work accordingly. In 2017, Tanaka decided to employ full-time workers, so that the shop would be taken care of when he was not around, as he needs to travel and meet investors in order to open more dream workshops. By May 2017, there were in total 3 full-time employees (General Manager, Head Chef and Marketing Manager) and approximately 150 volunteers who mostly served as dishwashers. In general, there will be two members in the kitchen (chef and dishwasher) and two on the floor (host and server). This paper aims to find out how the members describe Tanaka's philosophy, and how their ideas contributed to constructing a 
unique collective identity. I will first introduce the narratives of the General Manager and three members.

\section{General Manager: David}

In any type of organization, it is necessary to have a "missionary" or cultural broker who is able to efficiently communicate the corporate mission to the other members. In AKI Cambridge, one of the major players was the General Manager David, who was a former local financial analyst before travelling the world for six months. He decided to continue working at AKI after volunteering there for some time because he believed that he could achieve his dream, which was to have constant innovation by helping people and building up the community at AKI. After working at AKI for four years, he was appointed to the position of General Manager; Tanaka expected him to not only manage shop operations such as member management, but also innovate the shop and enrich the community to help free people from concern and create a stress-free environment.

David had a deep and nuanced understanding of the logics in Tanaka's philosophy and ultimate goals. From David's perspective, the language barrier between him and Tanaka is not a big issue, because he believed they shared similar goals. David was the only full-time employee among the three with limited Japanese ability; the others were English/Japanese bilingual. However, despite his language disadvantage, David's narratives about AKI demonstrate that he has a deep understanding of Tanaka's philosophy and passions. For instance, during our interview, David suddenly asked me, "What makes you happy?" I was not expecting to be asked questions and responded to him with "ordinary" answers, saying that it might make me happy to have a good job. He said "enjoyment is the ultimate purpose of life", and explained Tanaka's philosophy to me by pointing at his T-shirt, where a multi-panel comic sequence was drawn.

The story starts with a pig, the main character of the comic (and other AKI goods), wondering about his dream and future. The pig says, "Life is a funny thing, we all have some kind of drive to live life... that's called having a dream." It continues, "But are we actually enjoying our part of this dream?" "...we work so hard and we are so anxious about the future, we forget to enjoy the present". The cartoon then explains how eating jiro ramen or a "mammoth amount of food" is not because one needs to, but because one enjoys doing so. It portrays jiro ramen as a mountain, and expresses the feeling he felt at the top, "The view along the way to the top is marvellous. The things you see, the things you encounter". This phrase stresses the importance of feeling that "every moment of life is beautiful", 
rather than focusing on getting to the top. David used his own words to tell me that people need to find friends who can understand and support each other, and also mentors who can guide them in the right direction. David believes that members are at AKI in order to achieve their dreams, and they felt volunteering could show their values. This understanding is rooted in communication with both Tanaka's philosophy and David's own interpretations.

David was aware that one of the main goals of AKI was to increase the number of shared dreams. He said there has been profound improvement in this area as the number of shared dreams per day in 2016 was 50, which increased to 170 in 2017. Many other members I interviewed were also aware of this goal. The shared mission is a difficult task for the management to realize in many companies because messages may be interpreted differently by specific individuals, and even after they have been delivered they may not be believed by employees, or incorporated into their daily work. However, AKI's success shows that it is possible for shared missions to succeed. These to some extent benefit from the impact of simple wording and Tanaka's strong belief. In AKI's case, language did not cause any serious communication problems, as has been suggested in previous studies (Wong 1999; Sedgwick 2007) because the goal is simple, universally accepted, andsocially encouraged, and there is no one best way to achieve the goal. To achieve one's dreams by sharing them at the restaurant is a simple and understandable practice, and it is a positive act compared to increasing profits, which does not always benefit customers. There is also no complicated corporate manual defining how to increase the number of dreams, although there are several routine practices at AKI, such as the positive cycle programme.

David's positive feelings about Japanese and Tanaka demonstrate his respect and loyalty to Tanaka. He considered the positive cycle programme (a barter, non-monetary exchange system) created by Tanaka to be a "good cycle". He believed Japanese suppliers were loyal to buyers and vice versa, and he was surprised that this relationship did not change easily, even though there may have been other sellers with less expensive offers. He also felt that the Japanese are hardworking and willing to help each other, a sense that Tanaka's behaviour enhanced. He mentioned being surprised to see that one day Tanaka was on his knees, scrubbing the shop floor. David and other members followed Tanaka, even though they were not used to doing so, because they were a team. This demonstrates how Tanaka's behaviour influences the way members interpret AKI and Japanese culture in general. This reflects one of the characteristics in Japanese management called "sossensuihan [be a model]", where managers are expected to have 
higher moral values and normative behaviours in order that subordinates may observe and learn from them (Zhu 2015).

David's narrative shows his strong belief in Tanaka's philosophy and his willingness to improve the shop atmosphere and increase the number of shared dreams. David seems to have played a significant role in delivering Tanaka's philosophy, but how about other members? Do they feel the same way? The next section will discuss how three AKI members, including one volunteer, interpret Tanaka's philosophy, demonstrating how it is shared among them without strong and obvious institutional control.

\section{Members: John, Kazu, and Suzuki}

Among the three members interviewed, only Suzuki was a volunteer, while the other two were regular full-time employees. John and Kazu were Japanese/English bilingual and Suzuki could also speak two languages. I was surprised when I was interviewing David to see that almost all of the members were speaking in both Japanese and English.

John, the Marketing Manager, is in his early 20s and a Japanese Brazilian who studied in Japan for 19 years before going to university in Canada. He has been working as a volunteer at AKI since August 2016, and decided to join AKI because of his great experience working with Tanaka in one of Cambridge's Japanese festivals. AKI attracted John because it allowed him to have friends to support his dream and whom he could support in return. John said that he is still working to understand his dreams, but that he believes that staying at AKI gives him opportunities to find his answers. I felt that John was also one of AKI's missionaries because of his deeper understanding of Tanaka and his philosophy. For instance, when David was unsure about how to answer my questions during the interview, John was able to jump in, giving answers and even correcting David (such as about how many times a year AKI holds events, AKI's presence in Japan, etc., etc.). I only briefly interviewed him, but his responses and interactions with other members indicate that he shared Tanaka's beliefs and was willing to bring them to the world outside AKI.

Another employee, Kazu, is a Japanese American who aspires to run a business of ramen trucks around the world. He said that Tanaka attracts people from around the world and that his goal is to realize "zennjinruikeiei [management by human beings]", meaning that no one needs to be in charge and that everyone can stop by at AKI and leave. Kazu commented that AKI is not aiming to create a new business model but to create a better future. John and Kazu's responses indicate that Tanaka's philosophy has more facets than those that I heard from David or ascertained through 
researching secondary resources. Their understanding was enhanced by daily communications, through which they were able to input new information about his philosophy.

Suzuki is a Japanese volunteer in his forties who owns ramen shops in Japan and wanted to learn from Tanaka before opening his own shop in the United States. He told me that one of his ultimate dreams in life is to run a ramen truck business in underpopulated areas so that the elderly could eat ramen whenever and wherever they want, a model that would also foster local community development. He already had a blueprint for his goal, in which he uses a Social Networking System to broadcast the schedule of the ramen truck. One of his comments left a strong impression on me-he said that, at AKI, sharing a dream is an act of mandatory but also voluntary, behaviour. In other words, the act of sharing a dream is a free choice, but it sometimes needs a push.

The above shows that the AKI members have their own interpretations of Tanaka's philosophy, but all believed that the dream needs to be shared and that they were in the process of either finding out their dreams, or accomplishing them. Forming a group of people with similar beliefs and goals strongly influences an organization's collective identity. This is difficult not only in large-scale organizations where the majority of people do not know each other, but also in smaller organizations such as ramen shops, where the required tasks may be rather repetitive. One shop manager who works for another overseas Japanese ramen chain said that repetitive jobs and fewer changes in the shop make it difficult to motivate frontline workers. Sharing dreams might be an efficient tool to encourage such individuals because it allows their reasons for working to be not for monetary gain, but rather to create a better society and community.

This paper discussed how sacredness was created at AKI by its physical layout and members. The shop layout resembles a ceremonial place where believers face the place considered to be spiritually important. Customers are asked to enter one by one facing the kitchen where the chef is preparing ramen, which is considered to be their dreams, and after finishing eating they share their dreams facing the same direction. This may be understood as a unique religious practice in a business setting. How exactly do customers and AKI members interact? How about communication among AKI members? The next section provides a detailed description of how the corporate identity has been constructed through various ritualistic practices and symbols. 


\section{Construction of Identity: Rites and Symbols}

AKI's identity has been constructed from daily briefing sessions among the members, and by interaction with customers when they share their dreams. Tanaka's philosophy is that the symbolic ideology underlying these practices has not only constructed a unique organizational identity but also stressed the members' sense of belonging. This section uses data collected by participant observation during a weekday in May 2017 at the AKI shop.

\section{Briefing Session as Ritual Practice}

The briefing session, or "chorei" in Japanese, at AKI is almost a ritual act because it follows a certain order and embodies cultural significance. It is a procedure required on every working day. When I was interviewing one of the members at the kitchen counter, I saw David, the general manager, bring a white board and eraser and place them on a table located at the centre of the shop. It was around 4:40 pm, and soon after that, each member came to the table and wrote their daily, monthly, and yearly dreams. After David announced the start of the briefing (by saying "chorei"), all the members gathered at the centre of the shop. They were standing in a circle, rather than having managers facing subordinates, which is the traditional practice in many Japanese briefing sessions. When I glanced outside, there were already six customers lined up in front of the shop, although the session was occurring and there were more than twenty minutes before opening.

The briefing may appear casual from the outside, but it has certain rules. The first step was to sing several words in Japanese and English loudly, including "Irasshaimase" (Welcome to the shop), "Hai" (yes), "Arigatou gozaimashita" (Thank you for coming), and "Yorokonde" in Japanese and "Good job" in English. The first three words were quite common; many Japanese retailers use them to show gratitude to their customers. The third, "Happy to serve you", and the fourth, "Good job", to some extent represent Tanaka's philosophy. The third shows how Tanaka believes that life is all about enjoyment, and so members should be joyful serving the customers. The fourth shows how doing a "Good Job" is not only important for customers but also for members. A repetitive chorus with a cheerful (or loud from some perspectives) voice is another common practice among Japanese companies. Many managers believe that this practice enhances the awareness of the importance of serving customers, which will eventually help facilitate the penetration of corporate philosophy. 
Employees are expected to greet customers to show they are welcome.

The second step was to share their dreams, to discuss their progress and future plans. Anyone could start sharing their dreams in a daily, monthly, and yearly timeframe. Their dreams include cycling, reading 12 books in a year, planning to live with their loved ones, passing a term examination at college, and so on. Members report their progress, if there is any, and share the next step if their dreams have not yet been achieved. They are also encouraged to raise questions to the speaker if they feel they need clarification. For instance, after David said that his dream was to lead the shop in the best direction possible, one of the members asked him how he could achieve this. David said he would innovate the shop by creating a "chatmosphere" where people are able to freely chat about their dreams. These practices are similar to the traditional Japanese briefing in some ways, but differ because managers do not always talk first and subordinates are allowed to speak out.

The third step was to confirm each member's job task that day. David asked everyone to confirm his job position, such as kitchen, dishwasher, or shop floor. Typically, the general manager assigns tasks to each individual, but at AKI, members could also ask to confirm the task with David. This bottom-up communication might be common in some Japanese organizations, such as manufacturing sites, where the "professionals" (shoku'nin) who work under command have a strong say in production, but it is not generally considered good or appropriate behaviour in many other Japanese organizations. This style reflects Tanaka's philosophy, that no one should stay too long at AKI but rather should move fluidly, and that everyone should be "nakama" to one another.

The final step is usually a physical activity. On the day that I observed the briefing, it was a set of twenty pushups. After David announced the activity, everyone quickly dropped to the floor and counted for themselves, and while they were doing the pushups, the shop was so quiet that I could only hear their breathing. Those who had finished started getting back to their feet, and after confirming all members were up, they opened the shop.

There were several implications from the briefing session. The briefing has certain orders that do not change easily, and the repetition of regular practices allows them to remind themselves of their dreams and to share those dreams with others. This practice also shows the continuance and penetration of Tanaka's philosophy that colleagues should monitor one another, as they need to report their progress. This to created "positive" pressure on them. A pushup is one type of artificial obstacle that allows members to experience painful, but also enjoyable, moments. The briefing 
session then represents a mixture of freedom and control, where members could freely talk about any types of dreams, but also needed to come up with these dreams in the first place and to eventually accomplish them. It also shows the combination of pain and enjoyment, where employees need to go through the process of thinking about their dreams or to do physical activities such as pushups, and to feel enjoyment during the process. Besides interactions within groups, AKI also expands its practices out of their community, to the customers. The next section discusses how members and customers interact with each other and how this contributes to form a unique identity for AKI.

\section{Sharing of Dreams by Customers}

Like the briefing session, the way customers share their dreams has a certain order, and only selected people can do so. In this way, the shop encourages people to share their dreams voluntarily, but it is also selective. Like many Japanese restaurants, the shop has certain rules. The first is how to sit. Customers need to sit one by one in a row facing the kitchen. One of the Japanese customers said that this display looks exactly like a typical classroom in Japanese schools, where all students face the teachers. The display also resembles the way that religious people pray to sacred figures in worship spaces. These similarities may be unintentional, but the design nevertheless reflects an effort to improve the shop environment so that more customers are able to join their dream sharing.

Second is the process from the order to finishing the bowl of ramen. After customers select ramen, they help themselves to a glass of water, chopsticks, and a spoon. When the order is ready, the chef asks the customers if they require garlic, and then they are finally able to enjoy the ramen. After finishing, they choose either to share their dreams or leave the shop directly. If sharing, customers need to stand up, after which their bowls are checked. Interactions between shop members and the customers during the dream-sharing process play a significant role in creating boundaries between future AKI members and others.

Here is a scene I observed at AKI in May 2017. There were only four diners at the time, because the shop was closing soon. Three in their twenties were sitting near the kitchen, and one Japanese man in his thirties was sitting diagonally behind them. After the three customers finished their ramen, they stood up together and started to share their dreams in turn, facing the kitchen. The chef looked up into their eyes when the first customer started to share his dream about his study. After he finished, the chef and a shop floor member said "Good job!" For the second and the 
third customers, the members did the same thing. Showing their response and support was in order to create a comfortable environment for the customers in the hope that they would stop by again. When the Japanese man left the shop without sharing his dreams, the shop members were relatively quiet. This different attitude to some extent shows the normative control at the shop, where customers who finish their ramen and share their dreams are praised and others who do not participate gain little attention or support.

Whenever customers decided to share their dreams, many AKI members would feel that their hard work had paid off and that they were moving toward accomplishing Tanaka's goal of shared dreams. AKI members refrain from using verbal force to "coerce" customers into sharing dreams, but the above shows that there is still an informal and normative power influencing some customers to do so. Some customers told me that they felt awkward or even guilty for not sharing their dreams. This dream-sharing mechanism is in fact similar to the one in the briefing session, where the shop members had to come up with their daily, monthly and yearly dreams voluntarily under the normative control of Tanaka's philosophy. This power relation created boundaries between the members of AKI family and others.

\begin{abstract}
AKI Identity Building
Borrowing Hall and du Gay's concept that identity (1996) is a process, AKI identity may be understood as a negotiation process and a boundary-making process between the AKI family and outsiders. A group of people identify their "nakama" by criteria such as whether one is constantly chasing one's dreams and is willing to support and monitor each other's attempts to accomplish their own dreams. This identity has been constructed under the influence of Tanaka's philosophy, represented in a sacred space with symbols and enhanced by repetitive ritual practices. Collaboration in Tanaka's philosophy not only includes supporting "nakama", but also monitoring others' progress to give them positive pressure. Tanaka's emphasis on dreams comes from his frustration with the younger generations in Japan who seem to have lost hope after entering society. This makes his philosophy regarding AKI similar to that of social impact businesses - aiming to improve the greater good rather than achieving economic gain. Tanaka believes that sharing, reporting and giving feedback among "nakama" will help them to find new hopes in their lives.

This goal has been represented in every corner of the physical layout and mindsets of AKI's members. AKI formed a sacred space under the
\end{abstract}


influence of Tanaka's philosophy and showed how physical objects represent and resemble a religious ceremony. The table layout (facing towards the kitchen) and sitting order (in a row, one by one) resemble religious ceremonies where the spiritual authority stands facing the congregation, although it is slightly different in terms of how the participants (the customers) interact with the symbolic figure (the chef). Physical objects such as wall colour, paintings on the walls and chairs, displayed photos of various written dreams, and written numbers of shared dreams aim to show the emphasis on dreams and dream achievement. These physical objects and artefacts crate a unique atmosphere where people are informally required to choose whether they are in or out. AKI members' responses indicate they have different interpretations of Tanaka's philosophy; however, this does not deconstruct their collectivity, but rather enhances their collectiveness. They could sympathize with Tanaka's philosophy because they also have dreams and have no need to sacrifice their interests in this process. This consistency seems simple, but is difficult to practice in many business organizations, where in general the corporate missions seem to be out of reach and do not always satisfy employees' individual needs.

Ritual practices at AKI, such as the briefing session and interaction with customers, demonstrate how Tanaka's philosophy has been reconfirmed and emphasized. The briefing session allowed members to freely share their daily, monthly, and yearly dreams to ensure that everyone was getting the help they needed. To stimulate members' commitment, they would sometimes artificially create obstacles (such as a pushup) so that they could overcome them. These seem to be positive and voluntary, but nevertheless exerted normative control because they were required to present different dreams or goals on a regular basis, and need to accomplish them. Interaction with customers shows that while all customers were given the right to share their dreams, only selected ones were actually entitled to do so. Those who chose not to share frequently felt guilty because of the environment created by AKI members and other customers. These ritualistic practices aimed to instil Tanaka's philosophy into each individual through normative control behind the mask of freedom and openness.

Ritual practices and symbolic Tanaka philosophy have largely contributed to the negotiation and formation of AKI's identity. Tanaka's philosophy was written simply and has a positive message for those who have lost their direction in life. Members who have a deep understanding and sympathize with Tanaka's philosophy regularly confirm their commitment through briefing sessions that enhanced internal solidarity. Members also 
interact with customers to negotiate their boundaries according to certain criteria, such as how much ramen they finish, and whether they are willing to share their dreams. During the process of dream-sharing, two parties carefully explored who were their family, or "nakama," and who are not. This negotiation enhanced internal solidarity and external identity.

There are several implications in the case of AKI. First, it prompts us to revisit the formation process of identity. It shows that people who are struggling to find out who they are could also form a collective identity. In other words, people do not need to have concrete personal identity to form a collective identity. The findings also show a different picture from Koster's (2003) description of collective identity as a process of "reduction of individual identity", because AKI members do not compromise in expressing their originality, but rather search for their uniqueness together. AKI's identity formation also contributes to a better understanding of the ways in which ritual practices and symbols play a role in the formation of collective identity, and what kind of corporate identity non-profit-oriented philosophy may create.

Second, collective identity is a result of individual identification rather than a creation of management, and it does not always result in identity politics. Many have discussed how management should practice team-building rituals so as to enhance organizational integrity (Cilliers 2000; Whitney et al. 2004; West and Markiewicz 2008), but AKI's case shows that even without clear direction from management, employees are still able to form a collective identity so long as they have employee-friendly corporate missions and ritual practices. Some scholars have concerns that the distinction between insider and outsider may cause trouble between them (such as Rutherford 1990; Calhoun 1994; Keith and Pile 2004), but in this case it is the outsiders that are entitled to choose whether they want to join or not. More importantly, their purpose was not to stress their differences, but to invite outsiders to join their groups.

Lastly, the reasons why many young people were attracted to working as volunteers at AKI partly reflect a desire among younger generations across cultures to have and accomplish a dream, and to create bonds with communities that place less and less emphasis on monetary economy. Being volunteers at AKI is one way to strengthen ties to the organization (Manzo and Weinstein 1987; Martinez, and McMullin 2004). Many members felt safe sharing their dreams at AKI because no one would judge them, and because it is a platform for them to build up their networks and gain support from other members. Building bonds with the local community also attracts people who want to work for the greater good. This was clear from some of the members' dreams, where they indicated 
that they want their future businesses to be beneficial to society. Less emphasis on monetary gain is another attractive feature to people who feel financial burdens in Cambridge, a city composed of many start-ups and expensive, prestigious education institutions. The positive cycle programme created by Tanaka is an example of how AKI was not aiming for higher monetary gain, but rather to improve society without using money as the sole medium of exchange. In this way, AKI reflects some of the challenges we face in the modern organization and materialistic world, such as weak human bonding and powerless youth; AKI stands as an example of possible solutions to these modern dilemmas.

\section{Conclusions}

This paper examined how corporate identity in a Japanese jiro ramen shop has been constructed by ritual practices and symbols. The AKI philosophy, created by Tanaka, indicates that it is not simply a ramen shop, but a "dream workshop". At AKI, finishing one bowl of jiro ramen, which in general contains huge quantity of ingredients, is seen as being similar to the path of achieving one's dream-difficult but enjoyable.

Tanaka's philosophy has penetrated to the shop display and member beliefs and transformed the shop into a sacred space. AKI was full of messages encouraging people to share and achieve their dreams, openly displayed. The shop layout resembles the way a religious ceremony is held, where the respectful figure (the chef) faces the believers (customers) and there is a fixed order for their performance. Narratives of AKI members showed their deep understanding and sympathy with Tanaka's philosophy, because his belief does not conflict with members' individual interests but instead closely conforms to their goals, which forms a strong collective identity.

Ritual practices at the shop, including the briefing session and dream-sharing by the customers, help forge a unique AKI identity. These practices also evince the coexistence of control and freedom. AKI members may freely share any type of dream, but they are also required to do so and report their progress, and are monitored by other members. All customers were given the opportunity to share their dreams, but only those who fulfilled the requirements - to finish all the ingredients and had the confidence to share their dreams - were actually entitled to do so. Sharing dreams then is a free choice for members and customers, but not everyone is entitled to, and even once they gain the opportunity to do so, their progress will be monitored. 
AKI identity is a process in which members and customers negotiate their identities in a sacred space and aim to distinguish the AKI family from outsiders, but this is neither about identity politics nor about differentiating them from others, but rather about inviting others to be part of the community so as to achieve their goals. AKI thus exists as a case in which corporate identity is not a result of managerial control but rather of the creation of an informal group where people share various beliefs and goals under the same doctrine, Tanaka's philosophy. This shows that collective corporate identity can be formed without coercive managerial control if members have the same mentality and do not compromise their internal solidarity despite having diverse goals. This case provides insights into the process of identity formation and its relation to ritual and symbols, and can contribute to further exploration of the meaning and role of identity in an organization. It also implies that business managers should revise and adjust their goals and missions with consideration of the perspectives of employees, because only when they inherit these ideas and naturalize them into their own mindsets will internal solidarity become more robust.

\section{References}

Alvesson, M., \& D. Kärreman. (2001). The perfection or meritocracy or ritual of bureaucracy? HRM in a management consultancy company. 2nd International Conference on Critical Management Studies, Manchester.

Alvesson, M., \& Willmott, H. (2002). Identity regulation as organizational control: Producing the appropriate individual. Journal of management studies, 39, (5), 619-644.

Balmer, J.M.T. (1995). Corporate branding and connoisseurship. Journal of General Management, 21, (1), 24-46.

Balmer, J.M.T. \& Gray E.R. (2000). Corporate identity and corporate communications: creating a competitive advantage. Industrial and Commercial Training, 32, (7), 256-262.

Barley, S. R., \& Kunda, G. (1992). Design and devotion: Surges of rational and normative ideologies of control in managerial discourse. Administrative science quarterly, 37, 363-399.

Barth, F. (1998). Ethnic groups and boundaries: The social organization of culture difference. IL: Waveland Press.

Bernstein, D. (1984). Company image and reality: A critique of corporate communications. London: Taylor \& Francis.

Brown, A. (1997). A dynamic model of occupational identity formation. 
Retrieved from Education Online,

http://www.leeds.ac.uk/educol/documents/000000312.htm, on October $2,2017$.

Brown, T.J., et al. (2006). Identity, intended image, construed image, and reputation: An interdisciplinary framework and suggested terminology. Journal of the academy of marketing science, 34, (2), 99-106.

Calhoun, C.J. (1994). Social theory and the politics of identity, NJ: Wiley-Blackwell.

Cilliers, F. (2000). Team building from a psychodynamic perspective. SA Journal of Industrial Psychology, 26, (1), 18-23.

Cornelissen, J.P., \& Elving, W.J.L. (2003). Managing corporate identity: an integrative framework of dimensions and determinants. Corporate Communications: An International Journal, 8, (2), 114-120.

De Coulanges, F., \& Denis, N. (1873). The Ancient City: A Study on the Religion, Laws and Institutions of Greece and Rome, MA: Lee \& Shepard.

Dowling, G.R. (1986). Managing your corporate images. Industrial Marketing Management, 15, 109-115.

Durkheim, E. (1915). The Elementary Forms of the Religious Life, Translated by Swain, J.W., New York: The Free Press.

Erikson, E.H. (1959). Identity and the life cycle: Selected papers. Psychological issues, 1, 1-171.

Frost, P.J. et al., (eds.) (1985). Organizational Culture, Newbury Park: Sage.

Hall, S., \& Du Gay, P. (eds.) (1996). Questions of Cultural Identity, Newbury Park: Sage.

Hamada Connolly, T. (2013). Tri-level Analysis of a Corporate Feast and Business Ritual. Senri Ethnological Studies, 82, 25-42.

Howe, A.C. (2001). Queer pilgrimage: The San Francisco homeland and identity tourism. Cultural Anthropology,16, (1), 35-61.

Kaplan, D. (2009). The songs of the siren: Engineering national time on Israeli radio. Cultural Anthropology, 24, (2), 313-345.

Keith, M., \& Pile, S. (eds.) (2004). Place and the Politics of Identity. London: Routledge.

Kennedy, S.H. (1977). Nurturing corporate images-total communication or ego trip? European Journal of Marketing, 11, (3), 120-64.

Kitchen, P.J., et al. (2013). Corporate identity Antecedents and components: Toward a theoretical framework. Corporate Reputation Review, 16, (4), 263-284.

Koster, J. (2003). Ritual performance and the politics of identity: On the functions and uses of ritual. Journal of Historical Pragmatics, 4, (2), $211-248$ 
Lyons, B.J. (2005). Discipline and the arts of domination: rituals of respect in Chimborazo, Ecuador. Cultural Anthropology, 20, (1), 97-127.

Manzo, L.C., \& Weinstein, N. D. (1987). Behavioral commitment to environmental protection: A study of active and non-active members of the Sierra Club. Environment \& Behavior, 19, (6), 673-694.

Marwick, N. \& Fill, C. (1997). Towards a framework for managing corporate identity. European Journal of Marketing, 31, (5/6), 396-409.

Martinez, T.A., \& McMullin, S.L. (2004). Factors affecting decisions to volunteer in nongovernmental organizations. Environment and behavior, $36,(1), 112-126$.

Matsunaga, L. (2009). Kuukan no buranndinngu [Spatial branding] In Nakamaki, H., \& Hioki, K. (eds). Kaisha no nakano shukyou [Religion inside the company], Osaka: Touhou Shuppan.

Meyer, J. \& Rowan, B. (1977) Institutionalized organizations: formal structure as myth and ceremony. American Journal of Sociology, 83, $340-63$.

Nakamaki, H., \& Hioki, K. (eds.) (2009). Kaisha no nakano shukyou [Religion inside the company, Osaka: Touhou Shuppan.

Olins, W. (1990). Corporate identity: Making business strategy visible through design, MA: Harvard Business School Press.

Punjaisri, K., Evanschitzky, H. \& Wilson, A. (2009). Internal branding: An enabler of employees' brandsupporting behaviours. Journal of Service Management, 20, (2), 209-226.

Riketta, M. (2005). Organizational identification: A meta-analysis. Journal of Vocational Behaviour, 366, (2), 58-384.

Rutherford, J. (1990). Identity: community, culture, difference, London: Lawrence \& Wishart.

Sedgwick, M.W. (2007). Globalisation and Japanese Organisational Culture: An ethnography of a Japanese corporation in France, London: Routledge.

Simoes, C., Dibb, S., \& Fisk, R.P. (2005). Managing corporate identity: an internal perspective. Journal of the Academy of Marketing Science, 33, (2), 153-168.

Spickard, J. V. (2005). Ritual, symbol, and experience: Understanding Catholic Worker house masses. Sociology of Religion, 66, (4), 337-357.

Sumihara, N. (2009). "Omichi” to kigyou keiei ['Omichi (way)' and corporate management]". In Nakamaki, H., \& Hioki, K. (eds.) Kaisha no nakano shukyou [Religion inside the company], Osaka: Touhou Shuppan.

Van Riel, C.B.M. (1995). Principles of Corporate Communication, NJ: Prentice-Hall. 
West, M. A., \& Markiewicz, L. (2008). Building team-based working: A practical guide to organizational transformation. NJ: John Wiley \& Sons.

Whitney, D., et al. (2004). Appreciative team building: Positive questions to bring out the best of your team. IN: iUniverse.

Wong, H.W. (1999). Japanese Bosses, Chinese Workers: Power and Control in a Hong Kong Megastore, Richmond: Curzon Press.

Zepp, I.G. (1997). The new religious image of urban America: The shopping mall as ceremonial center. CO: University Press of Colorado.

Zhu, Y. (2015). Corporate ideology and store managers: Implication from a Japanese retailer. The Journal of International Public Policy, 36, 1-24. 
